\title{
Material Particulado y enfermedad cardiovascular
}

\author{
Sebastián García
}

Sin duda que hablar de contaminación ambiental y salud es un tema difícil en Chile y particularmente en la Región Metropolitana, ya que a pesar de ser motivo de debate en épocas electorales, no tiene finalmente un impacto visible para la ciudadanía. Es conocido el rol que juega la mala ventilación de la zona en donde se asentó la ciudad de Santiago en particular, así como el fenómeno de inversión térmica que empeora aún más la situación en épocas de bajas temperaturas. La erradicación de industrias contaminantes a sectores de mejor ventilación ambiental, alejados de los grandes centros urbanos, se contrapone a la necesidad de mantener y generar empleo y por otro lado implicaría una importante inversión por parte del empresariado ya sea en forma privada o subsidiada por el estado. El rol del estado a su vez parece muy relevante y a la vez inevitable, pero la legislación no necesariamente apunta en forma certera a las necesidades medioambientales. La fuentes de material particulado antropogénica son diversas ${ }^{1,2}$ y en general utilizan la combustión de materiales fósiles como el carbón, petróleo y sus derivados o gas natural como fuente de energía; la industria pesada, fundiciones, fábricas de cemento y cerámica, los medios de transporte motorizados, generan contaminación ambiental por material particulado y gases, plomo, sulfatos, nitratos, monóxido de carbono, asbesto y polvo desde las calles por el solo hecho de funcionar o circular; la obligatoriedad en el uso de convertidor catalítico en el parque automotriz que se incorpora a la circulación desde hace años, refleja un esfuerzo colectivo que a todas luces ha sido insuficiente, lo mismo ocurre con la pavimentación de las vías de circulación para vehículos motorizados que propende a una menor formación de polvo en suspensión o los sistemas de monitoreo ambiental es- tratégicamente ubicados y que determinan la necesidad de aumentar la restricción vehicular o incluso detener el funcionamiento de industrias contaminantes en los días de mayores índices de material particulado en suspensión, no se debe obviar entre las fuentes antropogénicas a las que se generan al interior de espacios habitados como son el uso de calefactores a parafina, chimeneas a leña o carbón y al tabaquismo ${ }^{3,4,5}$. Por otra parte el uso de combustibles ecológicos como ocurre hace años en Brasil con el alcohol obtenido de productos vegetales no parece sustentable por ahora en nuestro país, ya que obliga a destinar a este fin a grandes cantidades de productos de la agricultura. A su vez el gas natural, del cual no contamos como recurso natural sino que debemos importarlo tanto para el uso industrial como en los hogares, ha tenido una limitada aceptación, además, su uso no ha estado exento de accidentes por la inadecuada implementación del suministro y de los vehículos acondicionados para ello. La electricidad sigue siendo una opción atractiva en un país que es capaz de suplir las necesidades internas de esta forma de energía.

El estudio basado en parte de la población del registro $\mathrm{ICARO}^{6}$ nos entrega valiosa información acerca del impacto de la polución ambiental en lo que respecta a la necesidad de hospitalización por descompensación en los pacientes portadores de insuficiencia cardíaca, independiente de la etiología, al parecer mediado por el material particulado fino y grueso, definiendo una sub-población de mayor riesgo como lo son los diabéticos, hipertensos y pacientes añosos en general, aunque resulte paradójico el que menores de 74 años incrementen más su necesidad de hospitalización por descompensación que los de edad mayor; de igual interés resulta la observación de una latencia
Correspondencia:

Sebastián García B

Cardiología HCUCH.

sgarciabustos@hotmail.com 
de una semana aproximadamente a partir de la exposición a mayores índices de polución y la hospitalización definitiva. En una publicación española se señala el estrés térmico como un factor que influye en las variaciones estacionales de la enfermedad cardiovascular y a las variaciones en los ritmos circadianos según las horas de luminosidad en las distintas estaciones del año ${ }^{7}$. En la reflexión final se ha de considerar el que las enfermedades respiratorias también incre- mentan en frecuencia y gravedad en los meses fríos y con mayor contaminación, fenómeno "estacional" que también ha sido descrito por otros autores nacionales en lo que respecta a enfermedad cardiovascular, un mensaje que las autoridades en salud deben considerar tanto para los planes de contingencia como en la argumentación para una más definitiva y efectiva legislación de manejo medioambiental en la ciudades de mayor contaminación.

\section{Referencias:}

11. Samet JM, Dominici F, Curriero FC, Coursac I, Zeger SL. Fine particulate air pollution and mortality in 20 US cities 1987-1994. New Engl J Med 2000; 343: 1742-9

2. Pope CA 3rd, Muhlestein JB, May HT, Renlund DG, Anderson JL, Horne BD. Ischemic Heart disease events triggered by shortterm exposure to fine particulate air pollution. Circulation 2006; 114: 2443-8.

3. Román O, Prieto MJ, Mancilla F, Astudillo P, Dussaubat AM, Miguel C, et al. Daño cardiovascular por material particulado. Puesta al día 2008. Rev Méd Chile 2009; 137: 1217-24.

4. Sanhueza P, Vargas C, Jiménez J. Mortalidad diaria en Santiago y su relación con la contaminación del aire. Rev Méd Chile 1999;
127: $235-42$

5. Cáceres D, Adonis M, Retamal C, Ancic P, Valencia M, Ramos $\mathrm{X}$, et al. Contaminación intra-domiciliaria en un sector de extrema pobreza de la comuna de La Pintana. Rev Méd Chile 2001; 129: 33-42.

6. Castro. P, Wellenius G, Vera J, Cifuentes L, Verdejo H, Sepúlveda L, et al. Polución por material particulado fino (PM2,5) incrementa las hospitalizaciones por insuficiencia cardiaca. Rev Chil Cardiol 2010; 29: 306 - 314.

7. González E, Cabadés A, Cebrán J, López V, Sanjuán R, Echánove I, et al. Variaciones estacionales en los ingresos por infarto agudo de miocardio. El estudio PRIMVAC. Rev Esp Cardiol 2004; 57: $12-9$. 